\title{
Hot Forging and Hot Pressing of AlSi Powder Compared to Conventional Powder Metallurgy Route
}

\author{
Sayed Moustafa ${ }^{1}$, Walid Daoush ${ }^{1 *}$, Ahmed Ibrahim², Erich Neubauer ${ }^{3}$ \\ ${ }^{1}$ Department of Powder Technology at Central Metallurgical. Research and Development Institute (CMRDI), Cairo, Egypt; \\ ${ }^{2}$ Department of Mechanical Engineering, Faculty of Engineering at Helwan University, Cairo, Egypt; ${ }^{3}$ Department of Materials Re- \\ search at ARC Seibersdorf Research Center GmbH, Seibersdorf, Austria \\ E-mail: *waleeddaush@cmrdi.sci.eg
}

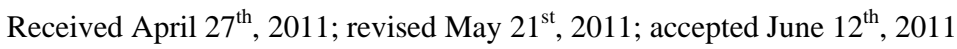

\begin{abstract}
Aluminum silicon alloy of composition $(\mathrm{Al}-25 \% \mathrm{Si}-3 \% \mathrm{Ni}-1 \% \mathrm{Fe}-2 \% \mathrm{Cu})$ was atomized using water atomization. The powders were cold compacted in a die to produce green cylinder compacts. Four consolidation processes were applied, namely; conventional sintering at $500{ }^{\circ} \mathrm{C}$, sintering followed by hot forging to obtain pistons, one step hot forging into pistons, and hot pressing. The microstructure of the sintered specimens showed inter-granular pores and oxide layers on particle interfaces of $84 \%$ relative density. When the sintered specimens were hot forged, both the inter-granular pores and oxide layers on particle interfaces almost disappeared and the relative densities increased up to about 95\%. The same microstructure is also obtained for the one step forged specimens, but the relative densities increased to about $97 \%$. However, the hot pressing specimens showed the presence of oxide layers on particle surfaces as well as few isolated pores. The relative density of the hot pressed specimens was about $90 \%$. Hardness and ultimate compression strength were measured. It is noted that the strongest bulk materials are those made by hot forging, followed by those made by hot pressing and the weakest bulk materials are those made by conventional sintering.
\end{abstract}

Keywords: Aluminum-Silicon Alloy, Powder Metallurgy, Hot Forging, Hot Pressing, Hardness, Compression Test

\section{Introduction}

Aluminum alloys are not only light weight materials, but also have excellent thermal conductivity, electrical conductivity, corrosion resistance, and workability. For these previous reasons, aluminum is widely used in structural components, electrical conductors, and consumer products. Among the newly developed aluminum alloys, rapidly solidified Al-Si alloys have superior mechanical properties, such as high strength, modulus, wear resistance and elevated temperature strength relative to conventional alloys [1]. Also Al-Si alloys are well known as typical high strength and lightweight materials, which are widely used in automotive and aerospace industries due to their higher strength; good wear resistance and low thermal expansion co-efficient [2].

The early technological development of hypereutectic Al-Si grew out of its application for internal combustion

*Associate Professor Walid. M. Daoush, Head of Powder Technology Division at Central Metallurgical R\&D Institute, Cairo, Egypt. engine blocks and pistons. This application uses all the properties for which the material is well known: high specific stiffness and strength, good hot strength, low thermal expansion and excellent wear resistance. The composition represents a compromise between castability and properties: it is close to the maximum silicon content in which sound products can consistently be obtained [3]. $\mathrm{Al}-\mathrm{Si}$ alloys are manufactured by casting and powder metallurgy methods. But, the relatively slower cooling rate, associated with the conventional casting process, produces coarse and segregated primary Si and/or eutectic Si in the Al-Si alloys [4]. Yet, the distribution and size of the primary silicon particles is more important than the overall silicon content of the alloy. Therefore, many efforts have been made in the microstructural modification of casting Al-Si alloys in order to achieve fine Si particles with the desired shapes and distributions. For example, techniques such as modification [5], ternary alloying [6], spray-deposition [2], or rapid solidification processing [7] have been applied to refine the primary Si 
crystals as well as to achieve their homogeneous distribution in hyper-eutectic Al-Si alloys. All the processes mentioned above, rapid solidification of metallic melts has been known to produce altered constitutional effects such as formation of supersaturated solid solutions, metastable intermetallic phases and even amorphous alloys [8]. Besides, the microstructural features (grain size and second phase/intermetallic inclusions) are also refined and the segregation effects are significantly reduced. A number of studies have been reported regarding fabrication of Al-Si alloys employing rapid solidification and hot-extrusion processes [9]. The increase in strength and wear resistance was achieved, as a consequence of rapid solidification and/or incorporation of ternary alloying transition elements.

The hypereutectic Al-Si alloys containing transition metals such as $\mathrm{Fe}, \mathrm{Ni}, \mathrm{Cr}, \mathrm{Zr}$ and $\mathrm{Cu}$ are unique materials due to their particular properties at elevated temperatures [10]. It is expected that alloys containing transition metals $(\mathrm{Fe}, \mathrm{Ni}, \mathrm{Cr} \cdots)$ can precipitate fine intermetallic compounds from rapidly solidified powder leading to a high-strength as well as increased wear resistance at elevated temperatures. The addition of Fe to rapidly solidified $\mathrm{Al}-\mathrm{Si}$ alloys results in dispersion of fine intermetallics and enhances rigidity, high temperature strength, and wears resistance. Addition of $\mathrm{Cr}$ minimizes the decrease of ductility and enhances forgibility [11].

The interfacial bonding between $\mathrm{Al}$ matrix and intermetallic compounds, and also the sharp corners of these compounds make it difficult to use these materials in the as-cast conditions. Several secondary processing steps need to be employed for the refinement of the primary phases and to get uniform distribution of intermetallic phases in the $\mathrm{Al}$ matrix. These include homogenization and controlled heat treatments along with further rolling or extrusion. However, their secondary processing is also a difficult proposition due to hard and coarse intermetallic phases [12]. To avoid these difficulties, spray forming processing route has been invariably used to produce such alloys [13]. The process involves atomization of liquid alloy, using a high energy inert gas jet, into a spray of fine droplets and its subsequent deposition of a substrate. The high cooling rate of the droplets during atomization and the unique mechanism of microstructural evolution during deposition give rise to rapid solidification effect in the microstructure and an equiaxed and refined grain morphology, along with a uniform distribution of refined secondary phases.

The powder forging process of rapidly solidified $\mathrm{Al}$ alloys was investigated in order to develop an inexpensive alternative process to produce high strength parts with complex shapes. It has been shown that the mechanical properties of powder forged parts are as good as those produced by extrusion [9]. Additionally, since powder forging produces a part in its final form directly from starting powders, without machining being necessary (near net shaping), the yield is high and less expensive in comparison with powder extrusion. Generally, it is necessary for powder consolidation to be performed by solid-phase diffusion at temperatures far below the melting points of the raw material powders, to ensure that the structural features obtained through rapid solidification are not lost. However, the surfaces of $\mathrm{Al}$ alloy powder are usually covered by an oxide layer approximately 10 $\mathrm{nm}$ thick. Unless this oxide film is ruptured and the fresh powder particle surfaces are allowed to come into contact with each other, it is not possible to obtain good bonding by diffusion. Therefore, the powder particles should be bonded together by plastic deformation during powder compaction step as well as forging step, and so understanding the deformation and compaction behaviors are very important to achieve good quality parts. The deformation behavior of powder metals during the compaction step is different from that of porous materials during the powder forging process. That is, the initial density is much lower in the compaction process (the initial state is powder) than in the powder forging process (the initial state is a sintered metal), there are sidings among the particles during the initial stage of compaction. Therefore, the yield function for powder metals should be different from that of the porous materials. In addition, most studies of powder forming used the yield functions for porous materials and ignored powder shape and size effects [14].

In this investigation, $\mathrm{Al}-25 \% \mathrm{Si}-3 \% \mathrm{Ni}-1 \% \mathrm{Fe}-2 \% \mathrm{Cu}$ alloy has been atomized with water in order to refine the primary silicon phase by rapid solidification. From these refined powders, automotive pistons of small size were fabricated using powder metallurgy route combined with hot forging and hot pressing processes.

\section{Experimental}

Aluminum silicon alloy of the chemical composition $\mathrm{Al}-25 \% \mathrm{Si}-3 \% \mathrm{Ni}-1 \% \mathrm{Fe}-2 \% \mathrm{Cu}$ was prepared by induction melting in graphite crucibles in air. Powders from this alloy were fabricated by superheated of the produced alloy in a graphite crucible up to $800^{\circ} \mathrm{C}$ and bottom pouring through a ceramic melt delivery nozzle of 6 $\mathrm{mm}$ diameter into a confined water atomizer operating at a pressure of $20 \mathrm{MPa}$. The high pressure water jets were directed against the molten stream. The melt flow rate, estimated from the operating time and weight of the atomized melt, was about $4 \mathrm{~kg} / \mathrm{min}$. The water flow rate, calculated from the water consumption rate, was about 200 l/min. Table 1 reports the atomization conditions adapted for powder fabrication. The size distribution of the alloy powder particles was measured by conventional 
Table 1 Water atomization parameters adapted for powder fabrication of the investigated Al-25\% Si-3\% Ni-1\%Fe$2 \% \mathrm{Cu}$ alloy.

\begin{tabular}{lc}
\hline \multicolumn{1}{c}{ Parameter } & Conditions \\
\hline Pouring temperature, ${ }^{\circ} \mathrm{C}$ & 800 \\
Nozzle angle & $35^{\circ}$ \\
Nozzle diameter, mm & 6 \\
Number of water jets & 4 \\
Molten stream flow rate, kg/min. & 4 \\
Water pressure, MPa & 20 \\
Water flow rate, $\mathrm{l} / \mathrm{min}$. & 200 \\
Water velocity, $\mathrm{m} / \mathrm{s}$ & 90 \\
\hline
\end{tabular}

mechanical sieving, and sieved powders with a specific size range of $180 \mu \mathrm{m}$ and $45 \mu \mathrm{m}$ were chosen for this investigation.

The produced powder was analyses by DSC at temperatures up to $600^{\circ} \mathrm{C}$ with heating rate of $10^{\circ} \mathrm{C} / \mathrm{min}$ in $\mathrm{Ar}$ atmosphere, in order to determine the solidus temperature of the powdered alloy.

Four consolidation processes were applied to obtain the bulk alloy, namely; conventional sintering, sintering followed by hot forging, one step forging, and hot pressing. In the first method, the powder was cold compacted into cylinder of $65 \mathrm{~mm}$ diameter followed by sintering at $500^{\circ} \mathrm{C}$ under $\mathrm{N}_{2}$ atmosphere for one hour. The second consolidation technique is hot forging of the sintered specimens made by the first method into pistons. The third process is carried out by heating the green cylinder compacts in $\mathrm{N}_{2}$ atmosphere for $10 \mathrm{~min}$. at $600^{\circ} \mathrm{C}$, and then hot forged into pistons. The size of piston was 65 $\mathrm{mm}$ in diameter, and $60 \mathrm{~mm}$ in height. The hot pressing process was carried out by filling the alloy powders into a graphite die and pre-compacted at a pressure of $5 \mathrm{MPa}$, placed inside a hot press from FCT Germany. After evacuation the chamber was filled with nitrogen and heated up with a heating rate of $10 \mathrm{~K} / \mathrm{min}$. At the same time the mechanical pressure was increased to $30 \mathrm{MPa}$. After achieving the temperature of $450^{\circ} \mathrm{C}$, a holding time of $90 \mathrm{~min}$ was maintained. The samples were cooled down to room temperature and removed from the graphite die. Figure 1 illustrates the hot pressing technique.

Extensive metallographic investigations were carried out for the atomized powders as well as the consolidated bulk materials using both optical and SEM microscopy. The density of the bulk materials was measured using water as a floating liquid and the sintered density $(\rho)$ were calculated by the Archimedes method using the following equation;

$$
\rho=\mathrm{W}_{\text {air }} /\left(\mathrm{W}_{\text {air }}-\mathrm{W}_{\text {water }}\right)
$$

where, $\mathrm{W}_{\text {air }}$ and $\mathrm{W}_{\text {water }}$ are the weight of the specimen in air and water respectively.

The hardness of the consolidated alloy was measured using Vickers hardness Tester under load of $1 \mathrm{~kg}$. The

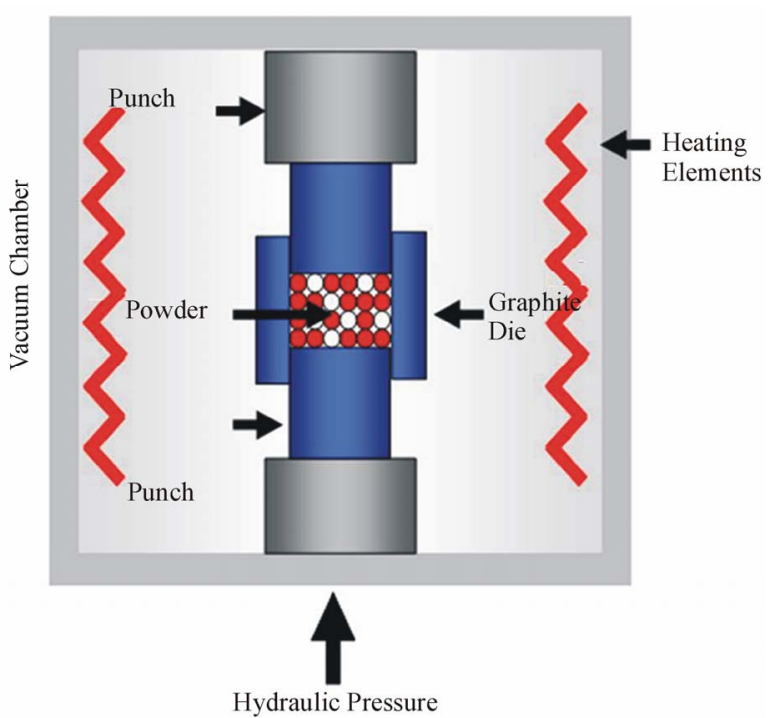

Figure 1. Schematic diagram illustrating the hot pressing Technique.

test was repeated five times at different points in each sample, and the values were compiled by calculating the average of the reported values of five sets of indentation tests. Compression tests of the consolidated materials obtained by the four methods were performed at room temperature with a cross-head speed of $10^{-3} \mathrm{~m} / \mathrm{s}$ and the values of the ultimate compression strengths were obtained.

\section{Results and Discussion}

\subsection{Atomized Powders}

Table 2 indicates the characteristics of the prepared atomized (Al-25\%Si-3\%Ni-1\%Fe-2\%Cu) alloy powders. The particles have size from 45 to $250 \mu \mathrm{m}$. Figure 2(a) shows the typical optical morphology of the as atomized (Al-25\%Si-3\%Ni-1\%Fe-2\%Cu) powder. The particle shape of the as-solidified powders were mostly spherical and had a smooth surface. Figures 2(b) and (c) show SEM images with different magnifications of the crosssectional area of the produced powder. The ultrafine microstructure is due to the small particle size of the produced powder and a consequence of the high solidification rate. Also there were no defects such as satellites or pores on the surface of the prepared powders. The primary silicon of the atomized powders became very fine and the silicon metal became very fine due to the high supercooling effect during atomization process [15]. However, it was difficult to distinguish between the primary Si and the eutectic Si particles in the microstructure of the produced powder.

DSC analysis was performed at temperature up to $600^{\circ} \mathrm{C}$ in argon atmosphere to measure the solidus tem- 

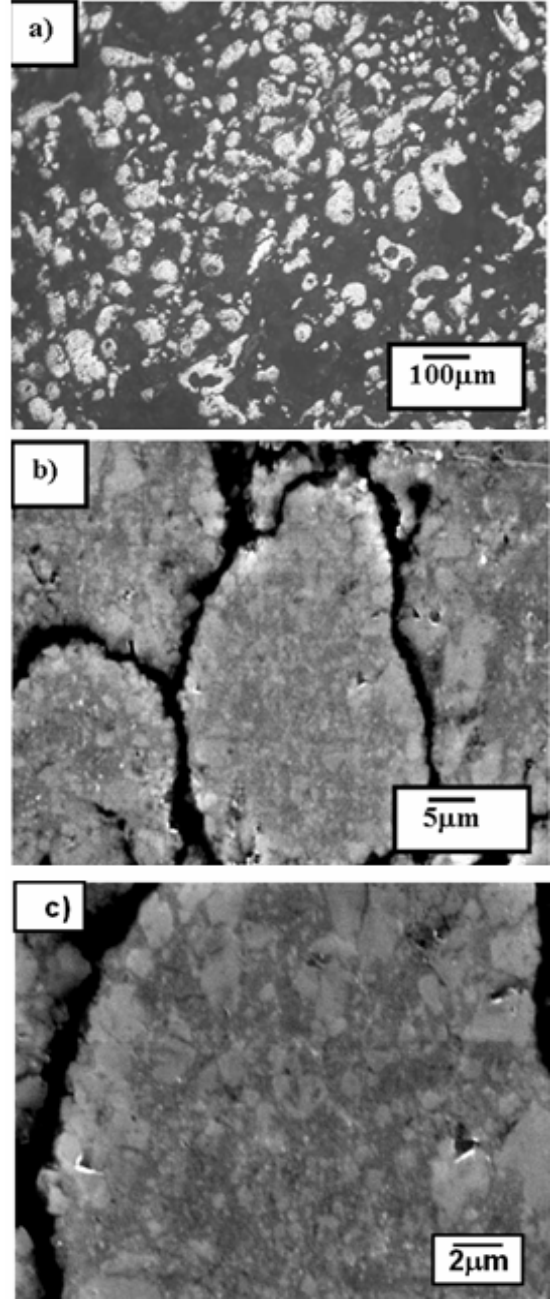

Figure 2 (a) Optical micrograph, (b) and (c) the cross sectional SEM micrograph with different magnifications of the produced atomized $\mathrm{Al}-25 \% \mathrm{Si}-3 \% \mathrm{Ni}-1 \% \mathrm{Fe}-2 \% \mathrm{Cu}$ alloy powder.

Table 2 Characteriation of the produced $\mathrm{Al}-25 \% \mathrm{Si}-3 \% \mathrm{Ni}-$ $1 \% \mathrm{Fe}-2 \% \mathrm{Cu}$ alloy powder.

\begin{tabular}{rc}
\hline Apparent density, g/cm & \\
Tap density, g/cm & 0.94 \\
Flow rate, s/50g & 1.16 \\
Mean grain size, $\mu \mathrm{m}$ & 45 \\
$\mathrm{D}_{10}$ & 45 \\
$\mathrm{D}_{50}$ & 106 \\
$\mathrm{D}_{90}$ & 180 \\
\hline
\end{tabular}

perature of the produced powder Al-25\%Si-3\%Ni-1\%Fe$2 \% \mathrm{Cu}$ alloy. Figure 3 shows the result of the DSC analysis and the measured solidus temperature is $572.3^{\circ} \mathrm{C}$.

\subsection{Microstructures and Densities of the Bulk Alloy}

Four sintering processing methods were applied in this

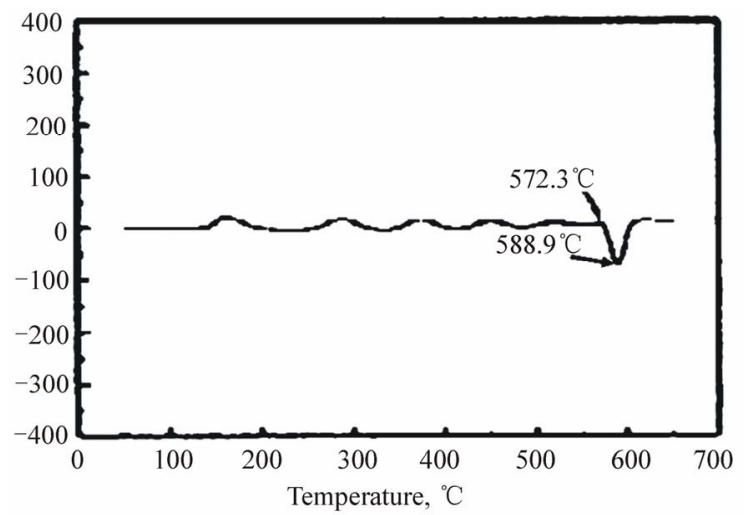

Figure 3. DSC analysis of $\mathrm{Al}-25 \% \mathrm{Si}-3 \% \mathrm{Ni}-1 \% \mathrm{Fe}-2 \% \mathrm{Cu}$ alloy powders.

investigation to obtain the bulk alloy. They are conventional sintering, sintering followed by hot forging, on step hot forging, and hot pressing. Figures 4 (a-d) illustrate the microstructures of the sintered alloys made by the four methods.

Figure 4(a) shows the microstructure of Al-25\%Si$3 \% \mathrm{Ni}-1 \% \mathrm{Fe}-2 \% \mathrm{Cu}$ alloy produced by conventional sintering. It is noted that there are many inter-granular pores as well as oxide layer on powder interfaces. In addition, the sizes of the primary silicon increased. The eutectic phase of $\mathrm{Al}-25 \% \mathrm{Si}-3 \% \mathrm{Ni}-1 \% \mathrm{Fe}-2 \% \mathrm{Cu}$ alloy and probably some other precipitates (e.g. $\mathrm{Al}_{2} \mathrm{Cu}, \mathrm{NiAl}_{3}, \mathrm{FeAl}_{3}$, etc.) are appeared and precipitated as several small particles distributed around the primary silicon.

Figure 4(b) illustrates the microstructure of the sintered followed by hot forging alloy to obtain pistons. It is clear that the inter-granular pores as well as oxide layer on powder surfaces almost eliminated. The same results are also obtained for the one step hot forging; see Figure 4(c). The only difference between the microstructures is the grain size of primary silicon, which is much smaller in case of one step hot forging. The reason for the disappearance of both inter-granular pores and oxide layers by hot forging is that the compacted materials was subjected to high deformation accompanied with materials flow to encompass with the new shape of pistons. The hot forging was carried out at temperature of $600^{\circ} \mathrm{C}$, which is higher than the solidus temperature of the investigated alloy in order to have some liquid phase to enhance the flow of the material during hot forging. It was found that during preliminary experimental work for obtaining pistons by hot forging, the material flow was very limited if the temperature was lower than the solidus temperature. The high deformation accompanied with material flow to cope with the piston die cavity resulted in disrupted the oxide layer and closed all pores under dynamic deformation effect of forging.

The microstructure of the hot pressing bulk alloy is in 

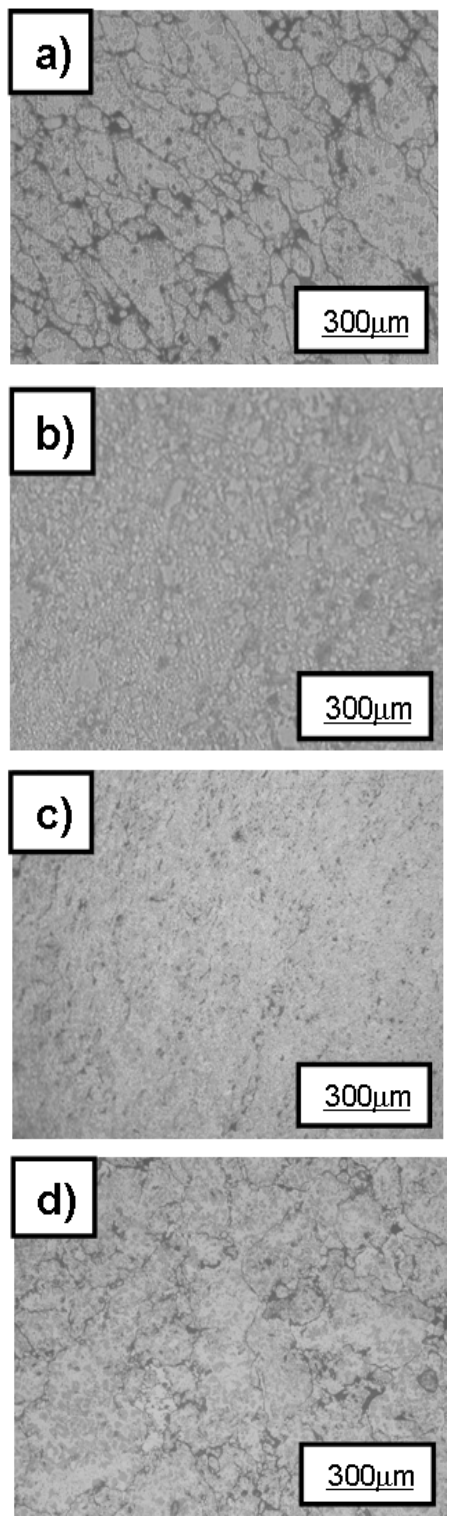

Figure 4. Microstructures of consolidated Al-25\%Si-3\%Ni$1 \% \mathrm{Fe}-2 \% \mathrm{Cu}$ alloy with different processes, where, a) by sintering, b) by sintering followed by hot forging, (c) by one step forging and (d) by hot pressing.

dicated in Figure 4(d). Both isolated and/ or inter-granular pores and the oxide layer on particle surfaces are existed, but the volume and numbers of pores are much less than those found in conventional sintering materials. The reason of this disappointing result of the hot pressing method may be attributed to the low holding temperature at $450^{\circ} \mathrm{C}$. The pores and the oxide layer could be eliminated if the hot pressing was carried out at $600^{\circ} \mathrm{C}$, i.e. above the solidus temperature.

The effect of consolidation process methods manifested itself on densities of the bulk alloy materials. Ta- ble 3 reports the relative densities of the four consolidation methods. The hot forged materials showed the highest relative densities followed by the hot pressing one, and the lowest relative density was recorded for the conventional sintering materials.

\subsection{Mechanical Properties}

The room-temperature mechanical properties hardness and ultimate compression strength (UCS) of the prepared Al-25\%Si-3\%Ni-1\%Fe-2\%Cu are presented in Table 4. It has been known that the addition of transition elements, such as $\mathrm{Fe}, \mathrm{Ni}$ and $\mathrm{Cu}$ increases the strength of the rapidly solidified Al alloys [7]. This combination of mechanical properties is directly related to the ultrafine grain size of the $\mathrm{Al}$ grains and $\mathrm{Si}$ particles, as seen in Figure 4. It was observed from the results of the UCS and the hardness values of the four consolidated Al-25\%Si-3\%Ni-1\%Fe-2\%Cu alloys as listed in Table 1 that, the strongest bulk materials are those made by hot forging, followed by those made by hot pressing and the weakest bulk materials are those made by conventional sintering. The reason of that is mainly due to the highest densities of the forged materials and the absence of the oxide layer on powder interfaces and the presence of oxide layer on powder interfaces decrease the bonding strength between particles $[16,17]$.

\subsection{Piston Forming}

The automotive pistons of $65 \mathrm{~mm}$ diameter, and $60 \mathrm{~mm}$ height could be fabricated by hot forging of either green or sintered cylinders. The green cylinders or sintered ones were heated at $600^{\circ} \mathrm{C}$ for $10 \mathrm{~min}$., in $\mathrm{N}_{2}$ atmosphere, and quickly transferred into a die has the shape of the required piston, and forged. The partially melted alloy helps the materials to flow and fill the cavity of the die to

Table 3. The density and relative density of the Al-25\%Si$3 \% \mathrm{Ni}-1 \% \mathrm{Fe}-2 \% \mathrm{Cu}$ alloy sintered by different consolidation processes.

\begin{tabular}{ccc}
\hline Consolidation Process & Density, g/ $\mathrm{cm}^{3}$ & Relative Density,\% \\
\hline Conventional sintering & 2.37 & 84.7 \\
Sintering and hot forging & 2.67 & 95.4 \\
One Step hot forging & 2.72 & 97.2 \\
Hot pressing & 2.53 & 90.2 \\
\hline
\end{tabular}

Table 4. Hardness and ultimate compression strengths of Al-25\%Si-3\% Ni-1\%Fe-2\% Cu alloy consolidated by different processes.

\begin{tabular}{ccc}
\hline Consolidation Process & Hardness, HV & UCS, MPa \\
\hline Conventional sintering & 24 & 89 \\
Sinterind and hot forging & 55 & 193 \\
One step hot forging & 76 & 210 \\
Hot pressing & 30 & 129 \\
\hline
\end{tabular}




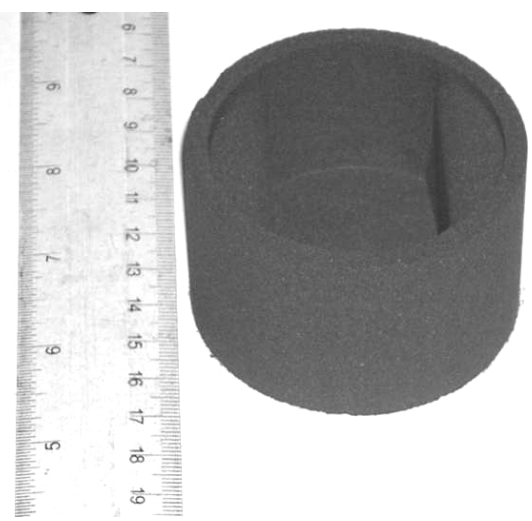

Figure 5. Photo of a simple piston produced by hot forging.

form the shape of the piston. Also, the presence of liquid phase disrupted the oxide film on the powders and increased the consolidation effect of forging to produce more sound bulk materials. Figure 5 illustrates the produced piston of simple shape. Hot forging process could be used to produce automotive piston without limitation in its chemical composition. Not only that, but also it is possible to increase both the productivity and the material yield of piston fabrication.

\section{Conclusions}

1) The atomization technique can be used to fabricate aluminum silicon alloy powder includes small content of transition metals such as nickel, iron and copper to enhance the mechanical properties. Very fine primary silicon particles were formed in the powder due to the cooling effect of the atomization technique.

2) The microstructure and the mechanical properties of the fabricated $\mathrm{Al}-25 \% \mathrm{Si}-3 \% \mathrm{Ni}-1 \% \mathrm{Fe}-2 \% \mathrm{Cu}$ alloy were investigated as a function of the fabrication process. Four consolidation processes were applied on the produced powder. The hot forging processes of either sintered or green compacts exhibited the largest densities and strengths. The conventional sintering showed the smallest densities and strength. But the hot pressed samples indicated intermediate properties.

3) The hot forging process could be used to fabricate automotive pistons with high productivity and without limitation in the chemical compositions of the alloy.

\section{REFERENCES}

[1] T. Hanlon, Y. N. Kwon and S. Suresh, "Grain Size Effects on the Fatigue Response of Nanocrystalline Metals," Scripta Materialia, Vol. 49, No. 7, 2003, pp. 675-690. doi:10.1016/S1359-6462(03)00393-2

[2] J. Zhou, J. Duszczyk and B. M. Korevaar, "Microstructural Features and Final Mechanical Properties of the Iron-Modified Al-20Si-3Cu-1 Mg Alloy Product Proc- essed from Atomized Powder," Journal of Materials Science, Vol. 26, No. 11, 1991. pp. 3041-3050. $\underline{\text { doi: } 10.1007 / \mathrm{BF} 01124840}$

[3] P. J. Ward, H. V. Atkinson, P. R. Anderson, L. G. Elias, B. Garcia, L. Kahlen and J. M. Rodriguez, "Semi-Solid Processing of Novel MMCs Based on Hypereutectic Aluminium-Silicon,” Acta Materialia, Vol. 44, No. 5, 1996, pp. 1717-1727. doi:10.1016/1359-6454(95)00356-8

[4] T. H. Lee and S. J. Hong, "Microstructure and Mechanical Properties of Al-Si-X Alloys Fabricated by Gas Atomization and Extrusion Process," Journal of Alloys and Compounds, Vol. 487, No. 1-2, 2009, pp. 218-224. doi:10.1016/j.jallcom.2009.07.108

[5] M. D. Hanna, S. Lu and A., Hellawell, "Modification in the Aluminum Silicon System," Metal Transaction A, Vol. 15, No. 3, 1984, pp. 459-469. doi:10.1007/BF02644969

[6] K. D. Woo and S.W. Kim, "Tensile Behavior of Al4\%Mg-0.4\%Sc-0.5\% Misch Metal Alloy at Room Temperature,” Metals and Materials International, Vol. 11, No. 2, 2005, pp. 95-99. doi:10.1007/BF03027452

[7] S. J. Hong and C. Suryanarayana, "Mechanical Properties and Fracture Behavior of an Ultrafine-Grained Al-20 wt\% Si Alloy," Metallurgical and Materials Transactions A, Vol. 36A, 2005, pp. 1-9.

[8] Z. C. Zhong, X. Y. Jiang and A. L. Greer, "Micro Structure and Hardening of Al-Based Nanophase," Materials Science and Engineering A, Vol. 226-228, No. 15, 1997, pp. 531-535. doi:10.1016/S0921-5093(97)80062-7

[9] H. S. Kim, "Yield and Compaction Behavior of Rapidly Solidified Al-Si Alloy Powders," Materials Science and Engineering A, Vol. 251, No. 1-2, 1998, pp. 100-105. doi:10.1016/S0921-5093(98)00635-2

[10] A. K. Srivastavaa, V. C. Srivastavab, A. Gloterc and S. N. Ojhad, "Microstructural Features Induced by Spray Processing and Hot Extrusion of an $\mathrm{Al}-18 \% \mathrm{Si}-5 \% \mathrm{Fe}-1.5 \%$ Cu Alloy,” Acta Materialia, Vol. 54, No. 7, 2006, pp. 1741-1748.

[11] R. Yearim and D. Shechtman, "The Structure of Rapidly Solidified Al-Fe-Cr Alloys,” Chemistry and Materials Science, Vol. 13, No. 11, 1982, pp. 1891-1898. doi:10.1007/BF02645932

[12] V. C. Srivastavaa, R. K. Mandalb, S. N. Ojhab and K. Venkateswarlu, "Microstructural Modifications Induced During Spray Deposition of Al-Si-Fe Alloys and their Mechanical Properties," Materials Science and Engineering $A$, Vol. 471, No. 1-2, 2007, pp. 38-49.

[13] Z. Gu, Y. Han, F. Pan, X. Wang, D. Weng and S. Zhou, "Production and Properties of a 90\%Si-Al Alloy for Electronic Packaging Applications," Materials Science Forum, Vol. 610-613, 2009, pp. 542-545. doi:10.4028/www.scientific.net/MSF.610-613.542

[14] N. Sridhar and A. Fleck, "Yield Behavior of Cold Compacted Composite Powders,” Acta Materialia, Vol. 48, No. 13, 2000, pp. 3341-3352. 


\section{doi:10.1016/S1359-6454(00)00151-8}

[15] H. Jones, "Gas-Atomised Aluminum Alloy Powders and their Products," Materials Science and Engineering A, Vol. 375-377, No. 15, 2004, pp. 104-111. doi:10.1016/j.msea.2003.10.077

[16] S. F. Moustafa, "Wear and Wear Mechanisms of $\mathrm{Al}-22 \% \mathrm{Si} / \mathrm{A}_{2} \mathrm{O}_{3}$ Composite,” Wear, Vol. 185, No. 1-2,
1995, pp. 189-195.

doi:10.1016/0043-1648(95)06607-1

[17] F. Wang, Y. Maa, Z. Zhanga, X. Cuia and Y. Jina, “A Comparison of the Sliding Wear Behavior of a Hypereutectic Al-Si Alloy Prepared by Spray-Deposition and Conventional Casting," Wear, Vol. 256, No. 3-4, 2004, pp. 342-345. doi:10.1016/S0043-1648(03)00412-5 